DE GRUYTER
DE

\title{
MICROENCAPSULATION OF VEGETABLE OIL: ALTERNATIVE APPROACHES USING MEMBRANE TECHNOLOGY AND SPRAY DRYING
}

\author{
Krisztina Albert, * GyUla VATAi, AND ANDRÁs Koris \\ Department of Food Engineering, Szent István University, Ménesi út 44, Budapest, 1118, \\ HUNGARY
}

\begin{abstract}
Microencapsulation technology is a method that is widely used in the food industry. By comparing the latest encapsulation techniques, a significant number of publications concern membrane technology. The term "membrane-based encapsulation" entails that the first step of the technique is the preparation of emulsion with the help of microporous membranes. Generally, in microencapsulation technologies, the wall material is dissolved in a continuous phase and oil is dispersed within it. In the present investigation, a new method of preparing microcapsules composed of vegetable oil and maltodextrin was developed. In the first step, the wall material (maltodextrin) was dissolved in oil and considered as a dispersed phase, subsequently, it was introduced into a continuous phase (water) through a microporous membrane. A comparative study was conducted between conventional microencapsulation techniques and one developed in our laboratory. The average particle size of microcapsules prepared by our method is smaller than the size allowed by other methods. After encapsulation preparation, fine-tuned microcapsules were produced by spray drying. However, the main disadvantage of our proposed technology is rapid membrane fouling, because of high concentrations of solute in the dispersed phase. This problem can be eliminated by judicious and systematic investigations.
\end{abstract}

Keywords: vegetable oil, microencapsulation, membrane technology, spray drying

\section{Introduction}

The controlled release of food ingredients at the right place and the right time is a key functionality that can be provided by microencapsulation. In food products, fats and oils, aroma compounds, vitamins, minerals, colourants and enzymes are encapsulated.

The process of the encapsulation of sensitive compounds consists of two steps: the first is often emulsion production: emulsification of core materials with dense solutions of wall material; the second is drying or cooling of emulsion by some chemical or mechanical process; and at the end of these processes microparticles can be obtained [1]. The two major industrial encapsulation processes are spray drying and extrusion [2]. Table 1 summarizes literature reviews that focus on these technologies, where the two steps of microencapsulation are performed by the combination of so-called membrane emulsification and spray drying.

Membrane emulsification (ME) is a relatively new, simple emulsion-production method which can be conducted with the use of a microporous membrane. Other emulsification processes within this category, besides ME and spray drying, include simple blending as well as homogenization; and secondary reactions that recover the capsules from the emulsion are interfacial

*Correspondence: albert.krisztina@etk.szie.hu polymerization, vacuum heat treatment, solvent diffusion and freeze drying. Different materials are used as the dispersed phase and wall materials of the microcapsules. The continuous phase is typically water.

\section{Experimental}

The main objective of this study was to initially prepare emulsions and form microcapsules using three different methods. The first approach was conventional membrane emulsification. The second one was conducted by a modified ME process. The third involved the use of a laboratory blender. In all three cases, the second step was the spray-drying technique to recover the microcapsules from the emulsions.

\subsection{Samples and Measurements}

All chemicals (maltodextrin, Tween-80 emulsifier) were procured from Shop.Builder, Hungary and SigmaAldrich, Germany. Commercial-grade sunflower-seed oil was purchased from a local market in the vicinity of Budapest.

\subsection{Membrane Emulsification Apparatus}

A cross-flow membrane emulsification system was used as the emulsification process (Fig.1). The apparatus included two manometers positioned at the opposite 
Table 1. Summary of examples from the literature of microencapsulation technologies.

\begin{tabular}{|c|c|c|}
\hline Emulsification & Secondary reaction & Dispersed phase / Wall material \\
\hline \multirow{6}{*}{$\begin{array}{l}\text { membrane } \\
\text { emulsification }\end{array}$} & & oil / polyvinylpyrrolidone (PVP) [3] \\
\hline & spray-drying & $\begin{array}{l}\text { fish oil / whey protein isolate (WPI), whey protein hydrolysate (WPH), sodium } \\
\text { caseinate, maltodextrin [4] }\end{array}$ \\
\hline & interfacial polymerization & benzene, xylene, liquid paraffin / terephthaloyl dichloride (TDC) [5] \\
\hline & vacuum heat treatment & oil / polyethersulphone (PES) [6] \\
\hline & solvent diffusion & oil / polycaprolactone (PCL), dichloromethane (DCM) [7] \\
\hline & freeze-drying & chloroform + curcumin / poly(lactic-co-glycolic acid) (PLGA) [8] \\
\hline \multirow{7}{*}{$\begin{array}{l}\text { blending and } \\
\text { homogenization }\end{array}$} & \multirow{6}{*}{ spray-drying } & extra virgin olive oil / gelatin, gum arabic, starch, lactose, maltodextrin [9] \\
\hline & & olive oil $+\alpha$-Tocopherol / maltodextrin, agave inulin, acacia gum $[10]$ \\
\hline & & $\begin{array}{l}\text { walnut and chia oil / maltodextrin, (hydroxypropyl)methyl cellulose [11] } \\
\text { ginger oil / cashew gum, inulin [12] }\end{array}$ \\
\hline & & $\begin{array}{l}\text { walnut oil / skimmed milk powder (SMP), SMP+Tween } 80, \mathrm{SMP}+\text { maltodextrin } \\
{[13]}\end{array}$ \\
\hline & & Nigella sativa oil / sodium caseinate, maltodextrin [14] \\
\hline & & chili seed oil / sodium octenylsuccinate starch, maltodextrin [15] \\
\hline & freeze-drying & Ziziphora clinopodiodes essential oil / whey protein isolate (WPI), pectin [16] \\
\hline
\end{tabular}

ends of the membrane to measure the drop in pressure along the membrane. The pressure of the dispersed phase was guaranteed by compressed air from an air pump which was injected from the outer surface of the membrane. The continuous phase was recirculated on the lumen side of the membrane by a pump. A rotameter, placed at the exit of the membrane, allowed the flow rate of the continuous phase to be measured.

\subsection{Microencapsulation Process}

Microcapsules were prepared by a tubular ceramic membrane with a pore size of $1.4 \mu \mathrm{m}$ (PALL Austria Filter $\mathrm{GmbH}$ ). The membrane was composed of $\alpha$ alumina and the surface area of the active membrane was $50 \mathrm{~cm}^{2}$. Cross-flow operation was adopted for emulsion production. The first emulsion was prepared using a conventional membrane emulsification technique. The wall material (maltodextrin) was dissolved in the continuous phase (water) and sunflower-seed oil was dispersed into it. The direction of flow of the dispersed phase was tangential with the surface of the membrane. Otherwise, in the second case the wall material was mixed with sunflower-seed oil. This mixture was considered as the dispersed phase and it was pressed through the membrane pores under pressure. In both cases the pressure of the dispersed phase was 2.5 bars and the recirculation flow rate of the continuous phase was $150 \mathrm{dm}^{3} \mathrm{~h}^{-1}$. In the third case the emulsion was prepared at room temperature using a laboratory blender at 2,000 rpm for 40 minutes.

\subsection{Spray Drying}

The emulsions prepared were spray dried with a laboratory-scale spray dryer (LabPlant SD-05) equipped with a nozzle of $0.5 \mathrm{~mm}$ in diameter. The pressure of the compressed air in terms of the flow of the spray was adjusted to 3.6 bars. The air temperature at the inlet was maintained at $180 \pm 5{ }^{\circ} \mathrm{C}$, and the feed rate was adjusted to $475 \mathrm{~cm}^{3} \mathrm{~h}^{-1}$, respectively. Emulsions were prepared during the spray drying process and were continuously stirred by a magnetic stirrer throughout. The microcapsules were collected from the collecting chamber and stored in darkness until analysed.

\subsection{Analysis of Microcapsules}

Following the emulsion preparation, the average droplet size and span value were measured by a FRITSCH Laser Particle Sizer ANALYSETTE 22 NanoTec. Each sample was analyzed three times and the average data reported. The span value was considered as an indication of the dispersity of the droplet size. The lower the span value, the more monodisperse the emulsion. A VHX-6000 digital microscope manufactured by KEYENCE was used to check the formation of microcapsules and evaluate their morphology.

\subsection{Surface-Oil Content and Microencapsulation Efficiency}

The procedure modified by Calvo et al. [9] to determine the surface-oil content and microencapsulation efficiency was employed to measure the amount of unencapsulated oil present on the surface of the powders. Briefly, $5 \mathrm{~g}$ of microcapsules were precisely

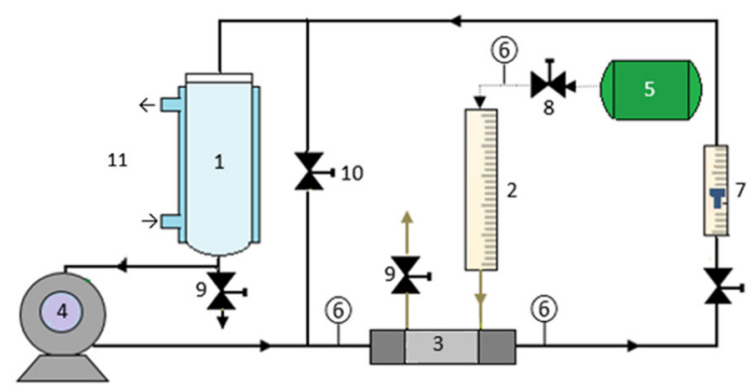

Figure 1. Experimental set-up for the cross-flow membrane emulsification process: (1) continuous phase tank, (2) graduated disperse phase tank, (3) membrane module, (4) pump, (5) compressor, (6) pressure meter, (7) rotameter, (8) pressure controller, (9) valve on drain, (10) valve, (11) heating / cooling (thermostat). 
Table 2. Results of emulsification.

\begin{tabular}{ll}
\hline $\begin{array}{l}\text { Conventional meth- } \\
\text { od using ME (1) }\end{array}$ & $\begin{array}{l}\text { Droplet size }=9.18 \mu \mathrm{m} \\
\text { Span }=1.5 \\
\text { Average flux }=368.36 \mathrm{dm}^{3} \mathrm{~m}^{-2} \mathrm{~h}^{-1}\end{array}$ \\
\hline $\begin{array}{l}\text { New method } \\
\text { using ME (2) }\end{array}$ & $\begin{array}{l}\text { Droplet size }=7.58 \mu \mathrm{m} \\
\text { Span }=1.72 \\
\text { Average flux }=159.29 \mathrm{dm}^{3} \mathrm{~m}^{-2} \mathrm{~h}^{-1}\end{array}$ \\
\hline $\begin{array}{l}\text { Laboratory } \\
\text { blender (3) }\end{array}$ & $\begin{array}{l}\text { Droplet size }=7.12 \mu \mathrm{m} \\
\text { Span }=1.88\end{array}$ \\
\hline
\end{tabular}

weighed in a beaker and $50 \mathrm{~cm}^{3}$ of hexane was added and shaken by hand for $15 \mathrm{~s}$ at ambient temperature to extract the superficial oil. The solvent mixture was then filtered through filter paper, and subsequently the unencapsulated oil was collected after evaporation of the hexane under a vacuum. To measure the total amount of encapsulated oil, the same procedure was conducted, but the powder of microcapsules in hexane as an extraction solvent was stirred for $4 \mathrm{~h}$ using a magnetic stirrer. For the production of microcapsules in oil, the encapsulation efficiency ( $E E)$ is an important parameter which is strongly related to the amount of oil on the surface, and was calculated using the following equation:

$$
E E=\frac{\text { Total oil }- \text { Surface oil }}{\text { Total oil }} \times 100
$$

\section{Results and Analysis}

The first part of this section presents the results in terms of the production of sunflower-seed oil/water emulsions by conventional and modified-membrane emulsification techniques using a laboratory blender, then the encapsulation efficiency and the physical characterization of the obtained microcapsules are presented.

\subsection{Results of Emulsification}

The results of particle-size measurements are

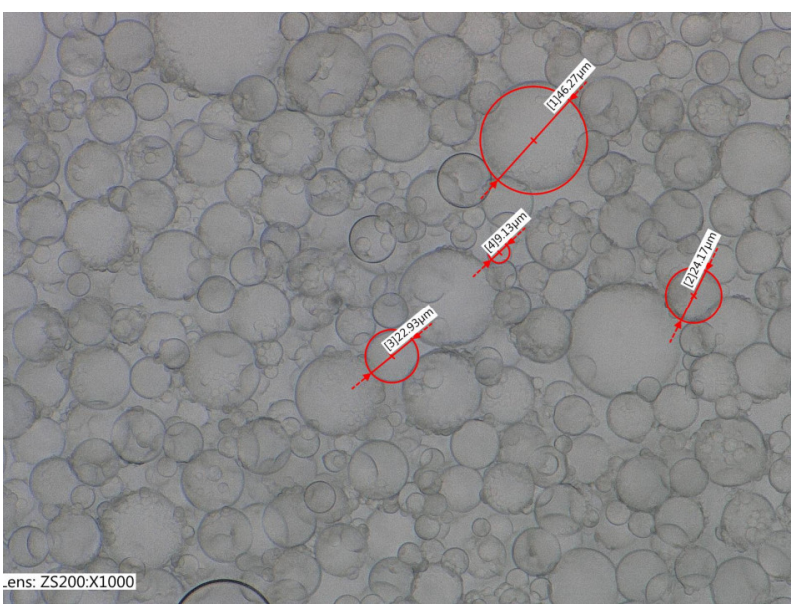

Figure 2. Microscopic image of emulsion sample at $1000 \times$ magnification.
Table 3. Oil encapsulation efficiency of microcapsules.

\begin{tabular}{ll}
\hline Conventional method with ME (1) & $36.4 \%$ \\
\hline New method with ME (2) & $34.5 \%$ \\
\hline Laboratory blender (3) & $28.2 \%$ \\
\hline
\end{tabular}

summarized in Table 2. The average droplet sizes were $9.18 \mu \mathrm{m}, 7.58 \mu \mathrm{m}$ and $7.12 \mu \mathrm{m}$ in the three different emulsification cases. The average droplet size of microcapsules prepared in the modified way, when the wall material was mixed with the dispersed phase, was lower than those prepared using the conventional technique.

In 2000, Joscelyne, along with his co-worker, reported that for membrane emulsification, the size of synthesized emulsion particles might be 2-10 times greater than the pore size of the membrane. The present investigators used a microporous membrane with a pore size of $1.4 \mu \mathrm{m}$ and it was found that in all three cases the average size of the synthesized microcapsules is in line with the conclusion reached by a previously mentioned research group [17]. As an example, the shape and morphology of synthesized microcapsules prepared by the modified ME methods are shown in Fig.2.

\subsection{Spray-Drying Results}

Sunflower-seed oil microcapsules were obtained by spray drying the oil-in-water $(\mathrm{O} / \mathrm{W})$ emulsions. The novelty of the approach adopted in the present study is that it utilizes membrane emulsification, which is a lowenergy technology, to produce sunflower-seed oil/water emulsions stabilized by maltodextrin which has been dried by spray drying. The results, represented in Table 3 , show that the encapsulation efficiency is enhanced by this modern method, the highest values correspond to microcapsules produced by this membrane technology. By comparing the encapsulation efficiency of microcapsules produced by conventional microencapsulation techniques with our laboratorydeveloped method, it should be mentioned that there is

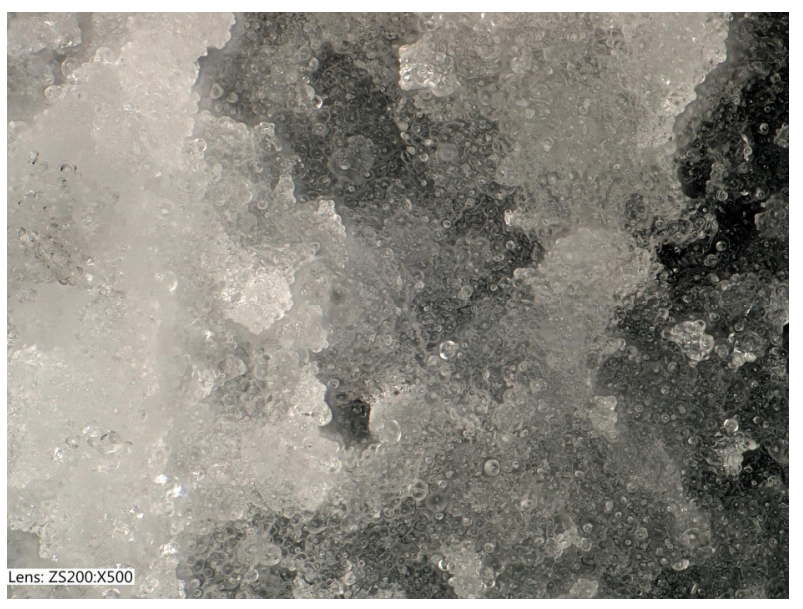

Figure 3. Image of microencapsulated sunflower-seed oil powder produced by conventional ME at $500 \times$ magnification. 


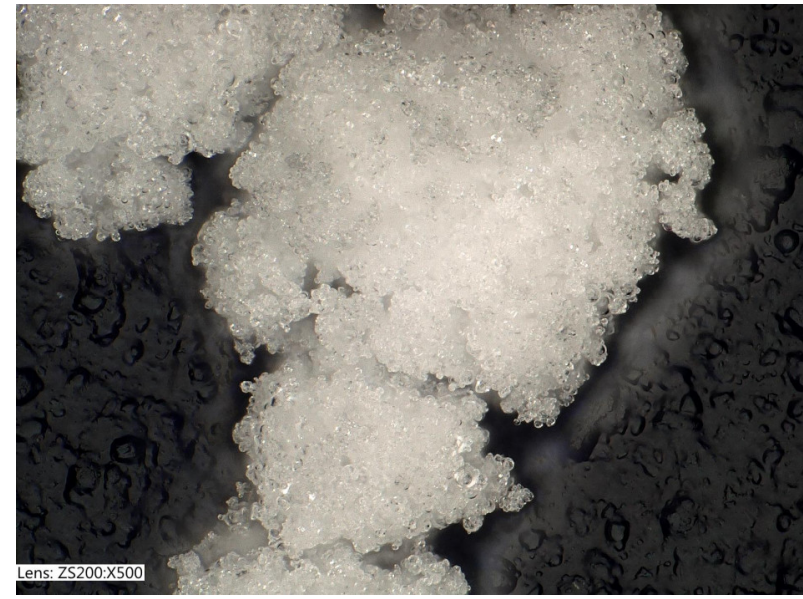

Figure 4. Image of microencapsulated sunflower-seed oil powder produced by modified ME at 500x magnification.

no significant difference in terms of encapsulation efficiency.

The surface and external morphologies of the microcapsules of sunflower-seed oil were studied using optical microscopy (Figs.3-5). In terms of particle morphology, the microstructures of the powders containing maltodextrin as a wall material were generally spherical in shape, homogeneous and exhibited a smooth surface as seen in the microscopic images. In 2015, Koç et al. [18] reported that the smooth surface of microencapsulated extra virgin olive oil using maltodextrin is related to the low-molecularweight sugar content of maltodextrin. These low molecular weight sugars may act as plasticizers on the surface of the particles during spray drying. In their study, when WPI (whey protein isolate) was selected as the wall material, the particles exhibited a rough surface compared to those containing maltodextrin.

\section{Conclusion}

Our work focused on basic research in terms of microcapsule production under a laboratory set-up. The main aim of the present investigation was to gain experience with regard to the preparation of microcapsules by membrane emulsification in combination with spray drying using a novel technique and to compare it with the conventional one. The operation of the process and its basic correlations were the primary foci of this paper. Based on the results obtained it is possible to draw up experimental plans that refine and optimize the process. The results of this work demonstrate that a modified membrane emulsification technique, in which the wall material is mixed with the dispersed phase and not with the continuous phase, combined with spray drying can be used to produce microcapsules of sunflower-seed oil that possess an appropriate oil-encapsulation efficiency.

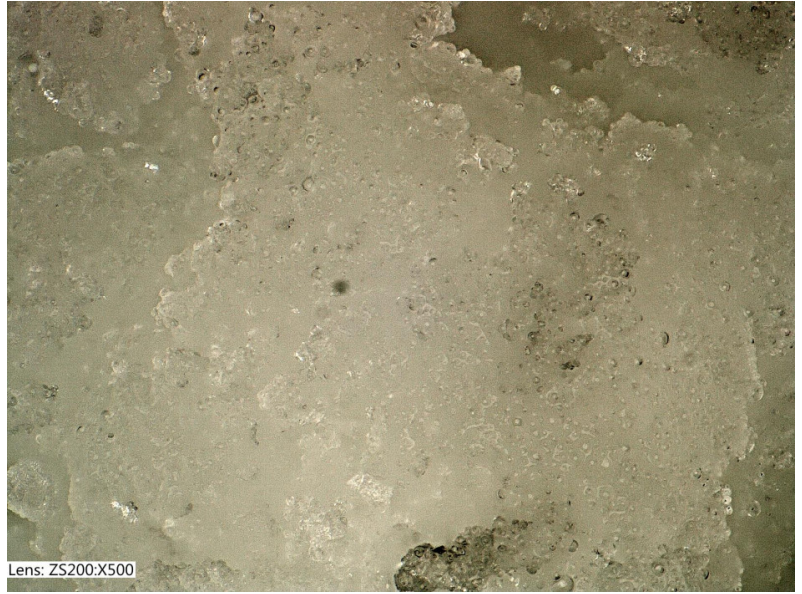

Figure 5. Image of microencapsulated sunflower-seed oil powder produced by a laboratory blender at $500 \times$ magnification.

\section{Acknowledgement}

The authors acknowledge the financial support of the ÚNKP-16-3-III New National Excellence Program of the Ministry of Human Capacities. They would like to thank KEYENCE Magyarország for providing the microscopic images.

\section{REFERENCES}

[1] Madene, A.; Jacquet, M.; Scher, J.; Desobry, S.: Flavour encapsulation and controlled release $-\mathrm{a}$ review, IJFST, 2006 41(1), 1-21 DOI 10.1111/j.13652621.2005.00980.x

[2] Gouin, S.: Microencapsulation: industrial appraisal of existing technologies and trends, TIFS, 2004 15(7-8), 330-347 DOI 10.1016/j.tifs.2003.10.005

[3] Choi, H.G.; Yong, C.S.; Yang, K.Y.: Oral solid preparation composition containing silymarin using membrane emulsification technique, and its production method, 2010, KR20120034264

[4] Ramakrishnan, S.; Ferrando, M.; Güell, C.: Food grade microcapsules produced by membrane emulsification, Procedia Engng., 2012 44, 1530-1533 DOI 10.1016/j.proeng.2012.08.855

[5] Chu, L.-Y.; Xie, R.; Zhu, J.-H.; Chen, W.-M.; Jamaguchi, T.; Nakao, S.-I.: Study of SPG membrane emulsification processes for the preparation of monodisperse core-shell microcapsules, J. Colloid Interface Sci., 2003 265(1), 187-196 DOI 10.1016/S0021-9797(03)00350-3

[6] Figoli, A.; Shanthana Lakshmi, D.; Piacentini, E.; Giorno, L.; Drioli, E.: Preparation of novel ionic liquid loaded polymeric microspheres by membrane emulsification process, Procedia Engng., 2012 44, 1287-1290 DOI 10.1016/j.proeng.2012.08.757 
[7] Imbrogno, A.; Piacentini, E.; Drioli, E.; Giorno, L.: Preparation of uniform polycaprolactone microparticles by membrane emulsification/solvent diffusion process, JMSC, 2014 467, 262-268 DOI 10.1016/j.memsci.2014.05.037

[8] Ho, T.H.; Dao, T.P.T.; Nguyen, T.A.; Le, D.D.; Dang, M.C.: Cross-flow membrane emulsification technique for fabrication of drug-loaded particles, Adv. Nat. Sci. Nanosci. Nanotechnol., 2013 4, 045008 1-6 DOI 10.1088/2043-6262/4/4/045008

[9] Calvo, P.; Hernández, T.; Lozano, M.; GonzálezGómez, D.: Microencapsulation of extra-virgin olive oil by spray-drying: Influence of wall material and olive quality, Eur. J. Lipid Sci. Technol., 2010 112(8), 852-858 DOI 10.1002/ejlt.201000059

[10] Turchiuli, C.; Jimenez Munguia, M.T.; Hernandez Sanchez, M.; Cortesferre, H.; Dumoulin, E.: Use of different supports for oil encapsulation in powder by spray drying, Powder Technol., 2014 255, 103108 DOI 10.1016/j.powtec.2013.08.026

[11] Martínez, M.E.; Curti, M.I.; Roccia, P.; Llabot, J.M.; Penci, M.C.; Bodoira, R.M.; Ribotta, P.D.: Oxidative stability of walnut (Juglans regia L.) and chia (Salvia hispanica L.) oils microencapsulated by spray drying, Powder Technol., 2015 270, 271277 DOI 10.1016/j.powtec.2014.10.031

[12]Fernandes, R.V.; Botrel, D.A.; Silva, E.K.; Borges, S.V.; Oliveira, C.R.; Yoshida, M.I.; Feitosa, J.P.; de Paula, R.C.: Cashew gum and inulin: new alternative for ginger essential oil microencapsulation, Carbohydrate Polym., 2016 153, 133-142 DOI 10.1016/j.carbpol.2016.07.096
[13] Shamaei, S.; Seiiedlou, S.S.; Aghbashlo, M.; Tsotsas, E.; Kharaghani, A.: Microencapsulation of walnut oil by spray drying: Effects of wall material and drying conditions on physicochemical properties of microcapsules, IFSET, 2017 39, 101-112 DOI 10.1016/j.ifset.2016.11.011

[14] Mohammed, N.K.; Tana, C.P.; Manap, Y.A.; Alhelli, A.M.; Hussin, A.S.M.: Process conditions of spray drying microencapsulation of Nigella sativa oil, Powder Technol., 2017 315, 1-14 DOI 10.1016/j.powtec.2017.03.04

[15]Wang, Y.; Liu, B.; Wen, X.; Li, M.; Wang, K.; Ni, Y.: Quality analysis and microencapsulation of chili seed oil by spray drying with starch sodium octenylsuccinate and maltodextrin, Powder Technol., $2017 \quad$ 312, 294-298 DOI 10.1016/j.powtec.2017.02.060

[16] Hosseinnia, M.; Khaledabad, M.A.; Almasi, H.: Optimization of Ziziphora clinopodiodes essential oil microencapsulation by whey protein isolate and pectin: a comparative study, Int. J. Biol. Macromol., $2017 \quad \mathbf{1 0 1}, \quad 958-966 \quad$ DOI 10.1016/j.ijbiomac.2017.03.190

[17] Joscelyne, S.M.; Tragardh, G.: Membrane emulsification - a literature review, JMSC, 2000 169(1), 107-117 DOI 10.1016/S0376-7388(99)00334-8

[18]Koç, M.; Güngör, Ö.; Zungur, A.; Yalçin, B.; Selek, İ.S.; Ertekin, F.K.; Ötles, S.: Microencapsulation of extra virgin olive oil by spray drying: Effect of wall materials composition, process conditions, and emulsification method, Food Bioprocess Technol., 2015 8, 301-318 DOI 10.1007/s11947-014-1404-9 